\title{
GAMBARAN PENGETAHUAN DAN SIKAP PADA REMAJA TENTANG BODYSHAMING DI SMAN 1 MARTAPURA
}

\author{
Devi Hairina Lestari ${ }^{*}$, Jannatul Fitri \\ Program Studi Diploma Tiga Keperawatan Stikes Intan Martapura, Indonesia \\ Email : devihairina89@hotmail.com
}

\begin{abstract}
ABSTRAK
Pendahuluan: Body shaming atau penghinaan tubuh orang lain tanpa dimengerti sering dilakukan oleh orang pada umumnya. Tujuan umum dari penulisan ini adalah untuk mengetahui bagaimana gambaran pengetahuan dan sikap pada remaja tentang body shaming di SMAN 1 Martapura. Desain penelitian yang digunakan adalah deskriptif, yaitu gambaran pengetahuan dan sikap pada remaja dengan body sahaming di SMAN 1 Martapura. Teknik sampling penelitian ini menggunakan Purposive Sampling. Dari hasil proses tabulasi silang sesuai tabel 4.6 didapatkan data kebanyakan dari responden memiliki pengetahuan cukup dengan berperilaku positif sebanyak $18(24 \%)$ responden dan pengetahuan cukup dengan berperilaku negatif sebanyak $17(22,6 \%)$ responden.
\end{abstract}

\section{Kata Kunci : Pengetahuan, Sikap, Remaja, Body Shaming}

\section{ABSTRACT}

Introduction: Body shaming or commenting on other people's physical flaws without realizing it is often done by people. The general desire of this article is to find out how the knowledge and attitudes of adolescents about body shaming at SMAN 1 Martapura. The research design used is descriptive, which is a description of knowledge and attitudes in adolescents with body stocking at SMAN 1 Martapura. The sampling technique of thisresearch was using purposive sampling. From the results of the cross tabulation process according to table 4.6 which uses the help of a computer device with the crosstab process it is realize that most of the respondents have sufficient knowledge with positive behavior of 18 (24\%) defendant and sufficient knowledge with negative behavior of 17 (22.6\%) respondents

\section{Keyword : knowledge, attitude, tenagers, body shaming}

Cite this as : $\quad$ Lestari, DH, Fitri, J. (2021). Gambaran Pengetahuan dan Sikap pada Remaja tentang Bodyshaming di SMAN 1 Martapura. Jurnal Ilmu Kesehatan Insan Sehat, 9(1), 47-50.

\section{PENDAHULUAN}

Body shaming atau penghinaan tubuh terhadap orang lain tanpa dimengerti sering dijalankan orang pada umumnya. Walaupun tidak ada hubungan fisik yang membebankan, melainkan body shaming sudah termasuk berbagai macam penghinaan secara lisan atau lewat kata-kata. Apalagi dalam kebiasaan diskusi bukan sedikit terdapat perkataan hinaan yang berakhir pada body shaming. Tindakan body shaming dapat membuat individu bertambah sadar bukan aman dan tidak nyaman tentang performa tubuhnya dan semenjak melindungi diri yang berhubungan dengan lingkungan ataupun masyarakat. Sisi lain dengan adanya body shaming, menimbulkan kata body positivity, yang adalah wujud penghargaan dari individu kepada wujud http://jurnalstikesintanmartapura.com/index.php/jikis fisik yang dimilikinya dan bagaimanapun mereka mendapatkan wujud fisik yang apa adanya. Sebutan ini merupakan bentuk tindakan kemasyarakatan agar memotivasi semua orang mempunyai pandangan yang baik tentang fisik mereka, mendapatkan wujud fisik mereka sendiri dan juga fisik orang lain jangan ada penilaian yang menyalahkan (Sastriyani,2005).

Terdapat 966 kasus penghinaan fisik atau body shaming yang diatasi oleh pihak kepolisian di seluruh Indonesia selama tahun 2018. Sejumlah 347 kasus yang sudah diatasi, dengan kekuatan perundang-undangan ataupun melalui perantara antara korban dan pelaku (News Detik. com,2018).Komisi Perlindungan Anak Indonesia (KPAI) mengatakan perilaku bullying, penghinaan dan body shaming di dunia pendidikan 
Devi Hairina Lestari, Jannatul Fitri, Gambaran Pengetahuan dan Sikap pada Remaja

menduduki peringkat keempat pada permasalahan tindakan kekerasan anak yang terjadi di Indonesia. Data yang didapatkan dari lembaga dunia Unicef tahun 2014 bahwa delapan dari 10 anak menghadapi bullying, penghinaan dan body shaming dan masalah bullying, penghinaan dan body shaming di Indonesia menduduki peringkat atau posisi keempat dalam masalah kekerasan anak. Data Komisi Perlindungan Anak Indonesia (KPAI) dari tahun 2011 hingga 2016 didapatkan sebanyak 253 kasus bullying, penghinaan fisik dan body shaming terdiri dari 122 anak yang menjadi korban dan 131 anak menjadi pelaku hingga Juni 2017. Kementerian Sosial memperoleh laporan sejumlah 967 kasus, 117 kasus yang mana dari kasus bullying, penghinaan fisik dan body shaming. Jumlah ini di luar kasus yang tidak dilaporkan. Pada tahun 2018 data KPAI mengatakan sebanyak 455 kasus pada data bidang pendidikan adalah kasus bullying, penghinaan fisik dan body shaming terdapat 161 kasus dan yang mana 41 kasusnya ialah kasus anak pelaku kekerasan dan bullying, penghinaan fisik dan body shaming sebanyak 228 kasus kekerasan yang sisanya adalah kasus tawuran pelajar dan kasus anak korban kebijakan. Keadaan seperti ini membuat khaatir semua orang apabila mengetahui pelaku oleh remaja (KPAI, 2016). Berdasarkan pengalaman saatberdinas di PUSKESMAS Martapura 2 dalam program skrining di SMAN 1 Martapura, peneliti mengukur tinggi badan dan berat badan siswa.

\section{METODE}

Penelitian menggunakan deskriptif, dengan populasi sebanyak 292 orang. Teknik sampel yang digunakan adalah Purposive Sampling dengan populasi sebanyak 292 orang. Analisis data disajikan dalam tabel distribusi frekuensi, dalam penelitian ini mengambil tempat SMAN 1 Martapura.

\section{HASIL}

\section{Tabel 1: Distribusi Frekuensi Responden Berdasarkan Umur di kelas XI SMAN 1 Martapura.}

\begin{tabular}{llll}
\hline No & Usia & Jumlah & Persentase \\
\hline 1 & 17 Tahun & 55 & 73,3 \\
\hline 2. & 18 Tahun & 20 & 26,7 \\
\hline & Total & 75 & $100.0 \%$ \\
\hline
\end{tabular}

(sumber : data primer yang diolah tahun2020)

Berdasarkan hasil penelitian, didapatkan umur responden di kelas XI SMAN 1 Martapura Tahun 2020, terbanyak adalah berumur 17 tahun yaitu sebanyak 55 responden $(73,3 \%)$.
Tabel 2: Distribusi Frekuensi Responden Berdasarkan Jenis Kelamin di kelas XI SMAN 1 Martapura

\begin{tabular}{lcll}
\hline No & Usia & Jumlah & Persentase \\
\hline 1 & Laki-Laki & 32 & 42,7 \\
\hline 2. & Perempuan & 43 & 57,3 \\
\hline & Total & 75 & $100.0 \%$ \\
\hline
\end{tabular}

(sumber : data primer yang diolah tahun2020)

Berdasarkan hasil penelitian, didapatkan jenis kelamin responden di kelas XI SMAN 1 Martapura tahun 2020, terbanyak adalah berjenis kelamin perempuan yaitu sebanyak 43 responden $(57,3 \%)$.

Tabel 3: Distribusi Frekuensi Responden Berdasarkan Sumber Informasi di kelas XI SMAN 1 Martapura

\begin{tabular}{clll}
\hline No. & $\begin{array}{l}\text { Mendapat Informasi } \\
\text { Tentang Body Shaming }\end{array}$ & Jumlah & Persentase \\
\hline 1. & Media Massa / TV & 32 & 42,7 \\
\hline 2. & Pelayanan Kesehatan & 26 & 34,7 \\
\hline 3. & Tidak Pernah & 12 & 16,0 \\
\hline 4. & Majalah dan internet & 5 & 6,7 \\
\hline & Total & 152 & $100.0 \%$ \\
\hline
\end{tabular}

(sumber : data primer yang diolah tahun 2020)

Berdasarkan hasil penelitian, didapatkan sumnber informasi tentang Body Shaming di kelas XI SMAN 1 Martapura Tahun 2020, terbanyak adalah dari Media Massa / TV yaitu sebanyak 32 responden $(42,7 \%)$. Sedangkan yang terendah adalah majalah dan interet sebanyak 5 responden $(6,7 \%)$.

Tabel 4: Distribusi Frekuensi Pengetahuan remaja tentang Body Shaming Di SMAN 1 Martapura

\begin{tabular}{cccc}
\hline \multicolumn{4}{c}{ Pengetahuan Remaja } \\
No. & & $\mathrm{N}$ & $\%$ \\
\hline 1. & Baik & 13 & 17,3 \\
\hline 2. & Cukup & 35 & 46,7 \\
\hline 3. & Kurang & 27 & 36,0 \\
\hline \multicolumn{2}{c}{ Total } & 152 & $100.0 \%$ \\
\hline
\end{tabular}

Sumber : Data Primer Yang Sudah Diolah (2020)

Berdasarkan tabel 4.4, mayoritas pengetahuan remaja berada pada kategori cukup yaitu sebanyak 35 $(46,7 \%)$ orang.

Tabel 5: Distribusi Frekuensi Sikap Remaja Pada Remaja Dengan Body Shaming Di SMAN 1 Martapura

\begin{tabular}{ccccc}
\hline \multicolumn{3}{c}{ Sikap Remaja } & N & \% \\
No. & & & 33 & 44 \\
\hline 1. & Positif & & 42 & 56 \\
\hline 2. & Negatif & & 75 & $100.0 \%$ \\
\hline & & Total &
\end{tabular}

Sumber : Data Primer Yang Sudah Diolah (2020) 
Berdasarkan tabel 4.5 di atas menunjukkan bahwa sebagian besar dari responden sejumlah 42 (56\%) memiliki perilaku yang negatif pada Body Shaming.

Tabel 6:Distribusi frekuensi responden berdasarkan tabulasi silang Pengetahuan Dan Sikap Remaja Pada Remja Dengan Body Shaming Di SMAN 1 Martapura

\begin{tabular}{ccccc}
\hline \multirow{2}{*}{ No } & $\begin{array}{c}\text { Pengetahuan } \\
\text { Remaja }\end{array}$ & \multicolumn{2}{c}{ Sikap Remaja } & \multirow{2}{*}{ Total } \\
\cline { 3 - 4 } 1 & \multirow{2}{*}{1} & Bositif & Negatif & \\
\hline 2 & Cukup & 5 & 8 & 13 \\
& & $0,6 \%$ & $10,6 \%$ & $17,3 \%$ \\
\hline 3 & Kurang & 18 & 17 & 35 \\
& & $13,3 \%$ & $22,6 \%$ & $46,7 \%$ \\
\hline \multirow{3}{*}{} & Total & 33 & 17 & 27 \\
& & $44 \%$ & $56 \%$ & $36,0 \%$ \\
\hline
\end{tabular}

Sumber : Data Primer Yang Sudah Diolah (2020)

Dari hasil proses tabulasi silang sesuai tabel 4.6 yang menggunakan bantuan perangkat komputer dengan proses crosstab diketahui bahwa sebagian besar dari responden memiliki pengetahuan cukup dengan perilaku positif sejumlah 18 (24\%)responden.

\section{PEMBAHASAN}

Sebagian besar dari responden memiliki pengetahuan cukup dengan perilaku positif sejumlah 18 (24\%) responden dan pengetahuan cukup dengan perilaku negatif sejumlah $17(22,6 \%)$ responden. Hal ini sejalan dengan penelitian (Marta, 2016) tentang sikap body shaming merupakan pengalaman emosi yang dialami seseorang apabila seseorang sadar bahwa tindakannya tidak sesuai dengan yang diinginkannya maupun lingkungan dan dirinya tersebut memandang bahwa orang lain mengenal kejadian itu. Pengetahuan dan Sikap body shaming ini bertumbuh dan berperan tidak hanya seperti perasaan namun berbentuk penilaian diri yang tumbuh karena adanya ketidakpuasan atas apa yang dipunyai seseorang

Pengetahuan dan Sikap body shaming dalam penelitian ini dapat mempengaruhi citra fisik yang bertentangan dari rasa malunya yang membuat individu mengalami body shaming gangguan makan, penilaian negatif terhadap fisiknya, seseorang yang mengalami sikap body shaming penyebabnya adalah individu tersebut terlalu mendengarkan kata-kata orang lain atau teman-temanya yang membuat citra fisiknya menjadi negatif, kalau individu tersebut citra fisiknya positif bisa menganggap hinaan atau cacian dari orang-orang tersebut hanya sebagai candaan.

Dampak dari sikap body shaming tidak ada manfaatnya atau banyak dampak negatifnya bahwa body shaming dapat bedampak kepada pemikiran negatif pada individu sehingga berdampak pada http://jurnalstikesintanmartapura.com/index.php/jikis kesehatan tubuhnya (Eva, 2016).

\section{KESIMPULAN}

1. Pengetahuan responden tentang Body Shaming mayoritas berada pada kategori cukup, yaitu sebanyak 35 responden $(46,7 \%)$.

2. Sikap responden tentang Body Shaming mayoritas berada pada sikap yang negatif, yaitu sebanyak 42 responden (56\%).

3. Gambaran pengetahuan dan sikap remaja pada remaja Tentang Body Shaming Di SMAN 1 Martapura dari hasil proses tabulasi silang yang menggunakan bantuan perangkat komputer dengan proses crosstab diketahui bahwa sebagian besar dari responden memiliki pengetahuan cukup dengan perilaku positif sejumlah 18 (24\%)responden dan pengetahuan cukup dengan perilaku negatif sejumlah 17 $(22,6 \%)$ responden.

\section{SARAN}

Peneliti mengharapkan penelitian ini dapat dimanfaatkan menjadi sumber informasi dan masukan dalam memberikan pelayanan asuhan keperawatan dan menjadi bahan penyuluhan kesehatan terhadap remaja serta menambah wawasan dan pengetahuan sehingga dapat memberikan kontribusi berarti bagi perkembangan ilmu keperawatan.

\section{DAFTAR PUSTAKA}

Suratun, H., Krisanty.P, Manurung.S. 2018. Diet HealthEducation Effect on ElderlyBehavior with Hipertension, Asian Journal of Applied Sciences (ISSN: 2321-0893). Volume 6, No.6.

Suratun, Ni Luh Putu Ekarini, Mamah Sumartini. 2018.Pengaruh Edukasi Gaya Hidup Sehat terhadap Pencegahan Dini Hipertensi pada Remaja. Jurusan Keperawatan Poltekkes Kemenkes Jakarta III.Vol 3, No 2.

Badan Penelitian Dan Pengembangan Kesehatan Kementrian RI. Riset Kesehatan Dasar Tahun 2018. Jakarta 2018.

Dinas Kesehatan Kota Banjarbaru.PravelensiHipertensi Kota Banjarbaru Tahun 2018. Banjarmasin. Banjarbaru, 2019.

Udjianti, J, 2011. Keperawatan Kardiovaskuler, Jakarta: EGC.

Triyanto. 2014. Pelayanan Keperawatan Bagi Penderita Hipertensi Secara Terpadu. Yogyakarta : Nuha Medika.

Nursalam. 2016. Konsep dan penerapan metodologi penelitian ilmu keperawatan. Jakarta salemba medika.

Notoadmojo. 2012. Metode Penelitian Kesehatan. Jakarta $:$ Rineka Cipta.

Susilo \& wulandari. 2011. Cara mengatasi hipertensi : Yogyakarta CV. AndiOffset.

Musyahidia. 2012. Hipertensi. Jakarta: PT. Gramedia 
Pustaka Utama.

Muhammadun. 2015. Hidup Bersama Hipertensi. In Books: Yogyakarta.

Purnomo, H, 2011. Pencegahan Dan Pengobatan PengobatanPenyakit Yang Paling Mematikan. BuanaPustaka: Yogyakarta.

Sarwono. 2012.Psikologi Remaja. Edisi Revisi. Jakarta: Rajawali Pers.

Wijoreni,N.A, 2014. Pengaruh Pendidikan kesehatan Tentang Gaya Hidup Sehat Terhadap Tingkat Pengetahuan dan Sikap Dalam mencegah Penyakit Tidak Menular,Surakarta: Artikel Publikasi Ilmiah Prodi Kesehatan Masyarakat Fakultas IlmuKesehatan UniversitasMuhammadiyah Surakarta.

Roshifanni,S, 2016. Risiko Hipertensi Pada Orang Dengan Pola Tidur Buruk.Jurnal Berkala Epidemiologi,Vol.4 No.3, September 2016
Brooker, Cristine., 2013. Kamus Saku Keperawatan, Jakarta; EGC

Dalimartha.S., 2012. Care Your Self Hipertension, Jakarta: Penebar Plus.

Depkes.2018. Profil Kesehatan Indonesia. Jakarta.

Thalib. 2015. Psikologi pendidikan berbasis analisis empiris aplikatif. Jakarta : kencana prenada media group.

Potter \& perry. 2014. Fundamental, Edisi 7 Buku 1. Jakarta : salemba medika.Mutia, L.,\& Leonard. 2013. Kajian penerapan e-learning dalam proses pembelajaran perguruan tinggi. Faktor excta.

Arikunto. 2015. Proseedur penelitian suatu pendekatan prktik, Jakarta : rineka cipta.

Wawan \& dewi. 2011. Teori dan pengukuran pengetahuan dan perilaku manusia. Cetakan II .Yogyakarta : Nuha Medika 